\title{
Cigarette graphic warning labels and smoking prevalence in Canada: a critical examination and reformulation of the FDA regulatory impact analysis
}

\author{
Jidong Huang, ${ }^{1}$ Frank J Chaloupka, ${ }^{1}$ Geoffrey T Fong ${ }^{2,3,4}$
}

\begin{abstract}
- Additional material is published online only. To view please visit the journal online (http://dx.doi.org/10.1136/ tobaccocontrol-2013-051170)

${ }^{1}$ Health Policy Center, Institute for Health Research and Policy, University of Illinois at

Chicago, Chicago, Illinois, USA ${ }^{2}$ Department of Psychology, University of Waterloo, Waterloo, Ontario, Canada ${ }^{3}$ School of Public Health and Health Systems, University of Waterloo, Waterloo, Ontario, Canada

${ }^{4}$ Ontario Institute for Cancer Research, Toronto, Ontario, Canada
\end{abstract}

\section{Correspondence to}

Dr Jidong Huang,

Health Policy Center, Institute for Health Research and Policy, University of Illinois at Chicago, 1747 West Roosevelt Road, Chicago, IL 60608, USA; jhuang12@uic.edu

Received 28 May 2013 Revised 7 October 2013 Accepted 15 October 2013 Published Online First 11 November 2013

\footnotetext{
To cite: Huang J, Chaloupka FJ, Fong GT. Tob Control 2014;23:i7-i12.
}

\begin{abstract}
Background The estimated effect of cigarette graphic warning labels (GWL) on smoking rates is a key input to the Food and Drug Administration's (FDA) regulatory impact analysis (RIA), required by law as part of its rulemaking process. However, evidence on the impact of GWLs on smoking prevalence is scarce.

Objective The goal of this paper is to critically analyse FDA's approach to estimating the impact of GWLs on smoking rates in its RIA, and to suggest a path forward to estimating the impact of the adoption of GWLs in Canada on Canadian national adult smoking prevalence. Methods A quasi-experimental methodology was employed to examine the impact of adoption of GWLs in Canada in 2000, using the USA as a control.
\end{abstract}

Findings We found a statistically significant reduction in smoking rates after the adoption of GWLs in Canada in comparison with the USA. Our analyses show that implementation of GWLs in Canada reduced smoking rates by $2.87-4.68$ percentage points, a relative reduction of $12.1-19.6 \%$; 33-53 times larger than FDA's estimates of a 0.088 percentage point reduction. We also demonstrated that FDA's estimate of the impact was flawed because it is highly sensitive to the changes in variable selection, model specification, and the time period analysed.

Conclusions Adopting GWLs on cigarette packages reduces smoking prevalence. Applying our analysis of the Canadian GWLs, we estimate that if the USA had adopted GWLs in 2012, the number of adult smokers in the USA would have decreased by 5.3-8.6 million in 2013. Our analysis demonstrates that FDA's approach to estimating the impact of GWLs on smoking rates is flawed. Rectifying these problems before this approach becomes the norm is critical for FDA's effective regulation of tobacco products.

\section{BACKGROUND}

The 2009 Family Smoking Prevention and Tobacco Control Act (FSPTCA) gave the US Food and Drug Administration (FDA) authority to regulate the manufacture, distribution and marketing of tobacco products. One key provision of the FSPTCA mandates more prominent warning labels for cigarettes and smokeless tobacco products. Specifically, FSPTCA requires pictorial or graphic warning labels (GWL) covering the top 50 percent (the minimum percent recommended by Article 11 of WHO Framework Convention on Tobacco Control) of the front and rear panels of cigarette packages (Pub L No. 111-31 \$201(a), 123 Stat 1776, 1842-45. 2009).
In June 2011, 2 years after FSPTCA became the law, FDA issued its first GWL regulations, which were later challenged by the tobacco industry, and subsequently struck down by the US Court of Appeals (see figure 1 for a timeline summarising the events related to FDA's GWL regulations). One of the major reasons that the Court ruled against FDA was because FDA did not provide any 'shred of evidence' that graphic warning images would "reduc[e] the number of Americans who smoke" (RJ Reynolds Tobacco Co v FDA, 696 F3d 1205, 1219, DC Cir 2012).

Despite the court ruling, the beneficial impact of warning labels, particularly large and prominent GWLs, has been well documented. ${ }^{12}$ Studies have shown that large GWLs on cigarette packages are an important source of health information for smokers and non-smokers. ${ }^{3}$ Exposure to GWLs reduce cigarette packet appeal, ${ }^{4}$ increase health knowledge, awareness and perception of risks associated with smoking, ${ }^{5-11}$ strengthen intentions to quit, ${ }^{5}$ encourage quit attempts, ${ }^{4} 7-912$ increase use of quitlines, ${ }^{13}$ prevent relapse, ${ }^{14}$ discourage smoking initiation ${ }^{4} 78$ and decrease the odds of being a smoker. ${ }^{12}$

While the literature on the effectiveness of GWLs is substantial, the evidence to date is focused more on individual level impact than population impact, and the outcomes examined have been more distal indicators of smoking behaviour than proximal indicators. And there is limited evidence on the impact of GWLs on smoking prevalence. The limited evidence for prevalence has critical implications for the ongoing legal and policy debates related to the proposed GWLs by FDA, particularly in light of recent failure by the Appeals Court in recognising a large body of evidence on individual-level outcomes, and putting undue weight on population-level impact provided by FDA, which was not adequately prepared.

As part of its rule-making process, FDA is required by law to assess all costs and benefits associated with its proposed regulations (known as the Regulatory Impact Analysis (RIA)), and to select the approach that maximises net benefits when regulation is necessary. Accurately assessing the impact of adopting GWLs on smoking prevalence is a key input to FDA's RIA. In the economic analysis conducted for its graphic warning label regulations, FDA relied on the Canadian experience to estimate the effect of GWLs on US smoking rates. FDA first compared trends in actual and estimated smoking prevalence in Canada and the USA from 1991 through 2009, projecting prevalence based 


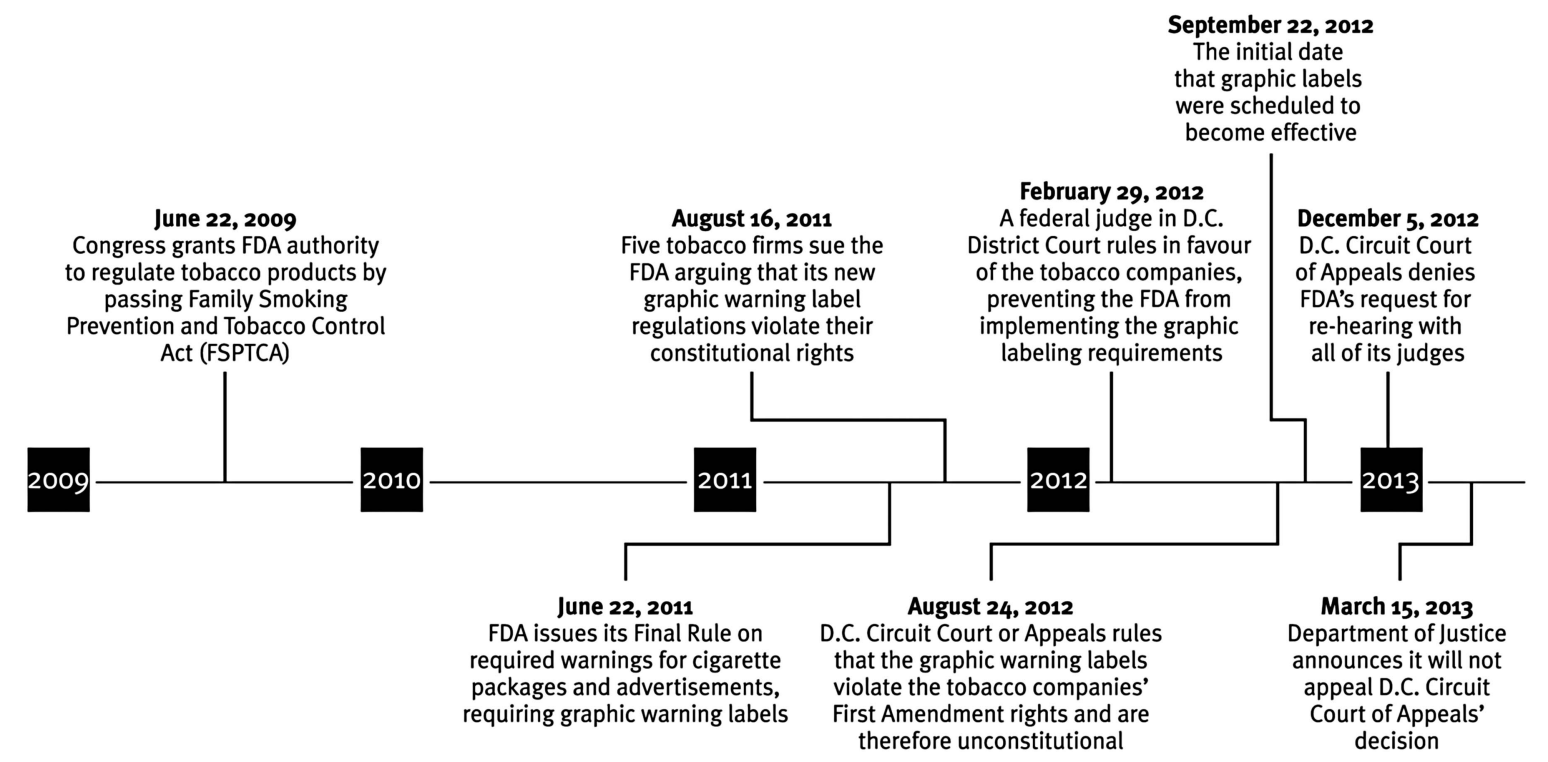

Figure 1 Timeline of Food and Drug Administration (FDA) graphic warning label regulations and relevant court decisions.

on changes in inflation-adjusted cigarette taxes in the two countries in the period before Canada adopted GWLs in 2000. The difference between the projected prevalence rates and the actual prevalence rates for the two countries between 2001 and 2009 was then assumed to be the result of Canada's GWLs. FDA estimated that the reduction in smoking rates attributable to GWLs to be 0.088 percentage points, equivalent to a relative reduction of $0.4 \%$ of the US smoking rate.

There are several major problems inherent in FDA's approach (see table 1 for a summary of those problems). First, FDA used cigarette excise taxes rather than actual prices paid by smokers to quantify the changes in smoking rates attributable to cigarette prices. Cigarette excise taxes, official cigarette price indices and actual prices paid by smokers may move in different directions. Controlling for cigarette taxes may attribute too much (little) of the differential decline in smoking rates to tax changes, and reduce (increase) the estimated impact of GWLs. Additionally, FDA's approach does not permit testing the statistical significance of changes in smoking rates resulting from the adoption of GWLs; as a result, it is impossible to ascertain whether the

Table 1 Flaws in FDA's regulatory impact analysis on graphic warning labels (GWL)

1 FDA used cigarette excise taxes rather than actual prices paid by smokers, which reduced the estimated impact of GWLs on smoking prevalence

Canada USA

Inflation-adjusted average cigarette taxes Increased by Increased by (2001-2009)

$123 \% \quad 117 \%$

Average inflation-adjusted official cigarette price indices (2001-2009)

Increased by Increased by $64 \% \quad 42 \%$ Average cigarette prices actually paid by Decreased by Increased by smokers (2002-2011)

$4 \% \quad 25 \%$

2 FDA did not utilise all available data points in the entire study period (19912009) in projecting smoking prevalence in the USA and Canada

3 It is impossible to ascertain whether the estimated impact of GWLs on smoking prevalence from FDA's approach is statistically different from zero.

4 FDA's approach does not allow causal interpretations of the effect of GWLs on smoking prevalence

FDA, Food and Drug Administration. estimated impact of GWLs is statistically different from zero. More importantly, FDA's approach does not allow causal interpretations of the effect of GWLs.

Since those problems in FDA's approach may have profound impact on the estimates of the impact of GWLs on smoking prevalence, it warrants a careful and thoughtful re-examination. In this paper, we critically analyse FDA's approach to estimating the impact of GWLs on smoking rates in its RIA of the required graphic warnings. Employing a quasi-experimental methodology, this paper adds to the growing evidence on the impact of GWLs by examining the change in smoking rates in Canada after it implemented GWLs, compared to the USA, where GWLs have not been implemented.

\section{METHODS}

\section{Difference-in-difference model}

To examine the impact of the implementation of GWLs on national adult smoking prevalence, we followed FDA's approach and used adult smoking prevalence data from the USA and Canada for 1991-2009, a period of 9 years before and after GWLs were introduced in 2000 in Canada. Comparing Canada as the treatment group (subject to GWLs after 2000) and the USA as the control group is an example of quasi-experimental methods that are widely used by economists and other policy researchers to estimate the causal impact of policy changes. ${ }^{15}$ The validity of these methods and their advantages over randomisation have been well documented. ${ }^{16-18}$ Quasiexperimental methods are particularly appropriate in this case in that it is impractical to randomise persons or jurisdictions to GWLs before they are adopted.

The reason that FDA focused on Canadian GWL experiences lie in three aspects: first, culturally and geographically, Canada provides a closer comparison for the USA than any other country; second, Canada is one of the first countries to adopt GWLs, thus, it provides more data points for examination; last, Canada's GWL policy is much more similar to what was proposed in FDA's GWL regulations than similar policies adopted in other countries and regions (see FDA Final Rule 36712). To analyse FDA's approach, we also focus on analysing Canadians' smoking prevalence data, as compared with that in the USA. 
In this paper, we use a specific quasi-experimental design, the difference-in-difference (DD) model, to assess, estimate and test the impact of GWLs on national adult smoking prevalence. The general DD model has the following specification:

$$
\begin{aligned}
\text { Outcomes }= & \beta_{1} \text { TreatmentGroup }+\beta_{2} \text { PostPolicyChange } \\
& +\beta_{3} \text { TreatmentGroup } \times \text { PostPolicyChange } \\
& +\beta_{4} \mathrm{X}+\mathrm{e}
\end{aligned}
$$

'TreatmentGroup' is a dummy variable with a value of 1 for jurisdictions or individuals subject to the policy being examined (in this case GWLs). The estimated coefficient, $\beta_{1}$, represents the difference between the treatment group (Canada) and the control group (the USA), which is not subject to the policy. 'PostPolicyChange' is a dichotomous variable with a value of 1 for data observed after policy implementation. The estimated coefficient $\beta_{2}$ shows the difference between the prepolicy and postpolicy periods. The key parameter is $\beta_{3}$, the interaction between the treatment group and the postpolicy change indicator, which reflects the estimated impact of the policy on the treatment group after implementation. Finally, $\mathrm{X}$ is a vector of control variables (cigarette prices in this case) and e is an idiosyncratic error term.

One of the advantages of the DD model is that the existence of fixed differences in unmeasured characteristics between the treatment and control groups does not affect the estimates. This is relevant to our analysis because the USA and Canada, despite their similarities, still have major differences.

\section{Model specification}

To illustrate the differences between our approach and FDA's approach, we estimated the following equation based on the general DD model outlined above, using the same smoking prevalence data for the same time period used by FDA.

$$
\begin{aligned}
(\ln (\text { SmokingRate })= & \text { Intercept }+\beta_{1} \text { Canada }+\beta_{2} \text { PostGWL } \\
& +\beta_{3} \text { Canada } \times \text { PostGWL } \\
& +\beta_{4} \ln (\text { ExciseTax } / \text { PriceIndex }) \\
& +\beta_{5} \ln (\text { Trend })+\text { error }
\end{aligned}
$$

The dependent variable in equation (2) is the national smoking rate in log form. Canada's smoking rates came from Health Canada's multiple surveys (including General Social Survey, Survey on Smoking in Canada, National Population Health Survey, and Canadian Tobacco Use Monitoring Survey), for years 1991-2009, and for the population aged 15 years and above. US smoking rates were for the population aged 18 years and above, for years 1994-2009, obtained from the National Health Interview Surveys. The smoking rates used in our analysis were obtained from Table 4 in FDA's Final Rule.

In equation (2), 'Canada' is a dichotomous variable with the value of 1 indicating Canada, the treatment group, and the value of 0 for the USA, the control group. 'PostGWL' is a dichotomous variable with the value of 1 indicating the post-2000 time period and the value of 0 otherwise. 'Canada*PostGWL' is the interaction between the treatment group (Canada) and the post-GWL time period. $\beta_{3}$ Represents the impact of GWLs on the treatment group (Canada) after GWLs were implemented. 'Trend' is a monthly trend variable used to capture the time trends in smoking rates, constructed based on the specific months in which key surveys were conducted in each country. This variable starts at 1 for January
1991, and increases by 1 each month. Data used in the analyses are presented in online supplementary appendix 1 .

\section{Controlling for cigarette tax/price}

Cigarette taxes/prices are one of the most important factors influencing smoking rates ${ }^{19}{ }^{20}$; it is thus important to control for their impact on smoking rates when assessing the impact of GWLs. In our analysis, we use three alternative measures to capture the influence of cigarette taxes/prices. The first is the inflation-adjusted cigarette excise tax rate in Canada and the USA. This variable is a population-weighted average of the sum of federal and provincial/territory cigarette tax rates for Canada, and the sum of the federal and population-weighted state cigarette excise tax rates for the USA. It covers the entire study period 1991-2009.

Controlling for cigarette excise taxes rather than prices ignores the complex relationship between tax rates, retail prices and the prices actually paid by consumers, and may bias estimates of GWLs. To account for these relationships, we use two alternative price measures. First, the official cigarette price index was used. The official US cigarette price index was based on the monthly tobacco and smoking products price index compiled by the Bureau of Labor Statistics, adjusted by the overall consumer price index to account for general inflation, and constructed as the average tobacco price index over the months specific to the US smoking surveys. Canada's official price index was constructed based on the Canadian monthly consumer price index component for cigarettes, adjusted by Canada's general consumer price index, and averaged over the months covered by the Canadian smoking surveys. The official price indices also cover the entire study period 1991-2009. The tax and official price indices were both normalised and indexed to 1 in November 2002. The US tax and price variables were normalised to a Canadian scale using the exchange rate between the US dollar and the Canadian dollar.

Official statistics on cigarette prices may not reflect the actual prices paid by smokers given opportunities to obtain untaxed cigarettes and opportunities for substitution to discount brands. To address this, we modified the official price index to incorporate actual prices paid by smokers, constructed from the selfreported prices collected in multiple waves of the International Tobacco Control Policy Evaluation Project (ITC) surveys in Canada and USA for the 2002-2009 period. The ITC prices were adjusted for inflation, and constructed as the average price in the months specific to surveys of smoking rates in each country. Similar to the other two measures, it was also normalised and indexed to 1 in November 2002. In our analyses, the last price measure was constructed by combining office price indices (1991-2001) and the ITC prices (2002-2009).

One of the key underlying assumptions of our DD models is that the decline in Canadian smoking rates relative to the decline in the USA is due to the GWLs since we do not control for changes in other tobacco control policies, and other timevariant factors that may influence smoking rates in both countries. Equation (2) also assumes that both countries had the same underlying trend in smoking, which may not be true. To relax this assumption, we re-estimated equation (2), adding an interaction between the trend and the 'Canada' variable, allowing for differential trends in the two countries.

\section{RESULTS}

Table 2 presents the estimated impact of GWLs on smoking prevalence. Model 1 controls for cigarette taxes, Model 2 controls for official cigarette prices and Model 3 controls for actual 
prices paid by smokers. Models 4, 5, 6 are similar to Models 1, 2,3 , respectively, but allow for different trends in the two countries.

The first row of table 2 shows estimates of $\beta_{3}$, the impact of GWLs implemented in Canada in 2000. They are statistically significant in all models and range from -0.13 to -0.22 . These estimates imply that GWLs reduced Canadian smoking prevalence between $12.1 \%(\exp (-0.13)-1)$ and $19.6 \%(\exp (-0.22)$ $-1)$. These estimates imply that if the USA had adopted similar GWLs as done in Canada, the smoking rates in the USA would have declined by $2.87-4.68$ percentage points, using the average pre-2001 smoking rates in the USA as the benchmark, which was 23.9 percentage points. Our estimated reduction in smoking rates in the USA is 33-53 times larger than the 0.088 percentage-point reduction estimated by FDA. Our estimates imply that if GWLs had been implemented in the USA in 2012, this would have led to a reduction of 5.3-8.6 million adult smokers in the USA in 2013, based on the number of adult smokers in the USA in 2011, which was 43.8 million. $^{21}$

The weaknesses in FDA's approach and sensitivity of its estimates are illustrated in table 3. Starting with the replication of FDA's approach (Model A), subsequent models modify FDA's approach by substituting the official price index for the cigarette tax (Model B), substituting the actual price paid by smokers for the tax (Model C), and by using data from the entire 19912009 period for both countries (Models D-F), rather than using only pre-2001 data, as done by FDA. Results in table 2 show that estimates based on FDA's approach vary considerably across models. Not only does the magnitude of the effect vary, but the direction also changes from model to model. More importantly, because FDA's approach does not permit statistical testing, it is impossible to ascertain whether the estimated impact of GWLs is statistically different from zero, let alone to make causal interpretations. There are some minor differences between our replication of FDA's analysis (Model A) and the estimates in FDA's analysis, which may be attributed to three factors. First, Canadian federal excise tax rates differ across different provinces/territories, FDA did not specify how they constructed Canadian federal tax rates. We used the province/ territory-population-weighted average as Canada's federal tax rate. Second, when constructing the annual tax rates, we took into account the effective dates of tax rates. FDA's final rule did not provide information on how annual tax rates were constructed. Third, there was no information in the final rule on how the trend variable was constructed for observations from surveys that span 2 years. We used the mid-point method. Despite these minor differences, the magnitude of the estimated parameters and their SEs from our replication (Model A) is very close to FDA's estimates (see online supplementary appendix 2 and 3 ).

\section{CONCLUSION AND DISCUSSION}

Since Canada adopted GWLs on cigarette packs in 2000, more than 40 countries have implemented similar prominent graphic health warning messages. ${ }^{22}$ A growing body of research has demonstrated the impact of GWLs on a number of outcomes, including health knowledge, risk perceptions, intentions to quit, quit attempts, use of quitlines, cigarette consumption and smoking relapse. ${ }^{2}$ This study adds to the growing body of evidence on the effectiveness of GWLs by examining their impact on smoking prevalence.

More importantly, our analyses exposed several serious methodological flaws in FDA's GWL RIA. Our analyses show that the GWLs adopted in Canada decreased adult smoking prevalence by $12-20 \%, 33-53$ times larger than FDA's estimates. Additionally, our estimates imply that if similar GWLs had been implemented in the USA in 2012, this would have led to a reduction of 5.3-8.6 million adult smokers in the USA in 2013.

Table 2 Estimated impact of graphic health warning labels using difference-in-difference models

\begin{tabular}{|c|c|c|c|c|c|c|}
\hline Ln(Smoking Rate) & Model 1 & Model 2 & Model 3 & Model 4 & Model 5 & Model 6 \\
\hline Canada \& Post-GWL interaction & $\begin{array}{c}-0.145^{* * *} \\
(0.0367)\end{array}$ & $\begin{array}{c}-0.163^{* * *} \\
(0.0425)\end{array}$ & $\begin{array}{c}-0.181^{* * *} \\
(0.0455)\end{array}$ & $\begin{array}{c}-0.129^{*} \\
(0.0644)\end{array}$ & $\begin{array}{c}-0.181 \text { ** } \\
(0.0722)\end{array}$ & $\begin{array}{c}-0.219 * * * \\
(0.0750)\end{array}$ \\
\hline Canada dummy & $\begin{array}{l}0.229 * * * \\
(0.0389)\end{array}$ & $\begin{array}{l}0.137^{* * *} \\
(0.0320)\end{array}$ & $\begin{array}{l}0.128^{* * *} \\
(0.0343)\end{array}$ & $\begin{array}{c}0.319 \\
(0.290)\end{array}$ & $\begin{array}{c}0.0405 \\
(0.317)\end{array}$ & $\begin{array}{c}-0.0833 \\
(0.332)\end{array}$ \\
\hline Post-GWL dummy & $\begin{array}{c}0.00610 \\
(0.0332)\end{array}$ & $\begin{array}{c}-0.0257 \\
(0.0366)\end{array}$ & $\begin{array}{c}-0.0478 \\
(0.0385)\end{array}$ & $\begin{array}{r}-0.00430 \\
(0.0474)\end{array}$ & $\begin{array}{r}-0.0133 \\
(0.0550)\end{array}$ & $\begin{array}{r}-0.0194 \\
(0.0590)\end{array}$ \\
\hline In(Monthly Trend) & $\begin{array}{c}-0.114 * * * \\
(0.0175)\end{array}$ & $\begin{array}{c}-0.101^{* * *} \\
(0.0196)\end{array}$ & $\begin{array}{c}-0.0994^{* * *} \\
(0.0216)\end{array}$ & $\begin{array}{c}-0.0972 \\
(0.0578)\end{array}$ & $\begin{array}{c}-0.120^{*} \\
(0.0667)\end{array}$ & $\begin{array}{c}-0.142^{*} \\
(0.0701)\end{array}$ \\
\hline In(Index ExciseTax) & $\begin{array}{c}-0.172^{* * *} \\
(0.0450)\end{array}$ & & & $\begin{array}{c}-0.178^{* * *} \\
(0.0491)\end{array}$ & & \\
\hline In(Pricelndex w/o ITC Price) & & $\begin{array}{c}-0.135 * * \\
(0.0612)\end{array}$ & & & $\begin{array}{c}-0.130^{*} \\
(0.0649)\end{array}$ & \\
\hline In(Pricelndex w ITC Price) & & & $\begin{array}{r}-0.0715 \\
(0.0709)\end{array}$ & & & $\begin{array}{c}-0.0623 \\
(0.0732)\end{array}$ \\
\hline Canada \& trend interaction & & & & $\begin{array}{c}-0.0197 \\
(0.0628)\end{array}$ & $\begin{array}{c}0.0218 \\
(0.0711)\end{array}$ & $\begin{array}{c}0.0479 \\
(0.0746)\end{array}$ \\
\hline Constant & $\begin{array}{l}3.511 * * * \\
(0.0789)\end{array}$ & $\begin{array}{l}3.540 * * * \\
(0.0913)\end{array}$ & $\begin{array}{l}3.573 * * * \\
(0.0967)\end{array}$ & $\begin{array}{l}3.429 * * * \\
(0.274)\end{array}$ & $\begin{array}{l}3.631 \text { *** } \\
(0.308)\end{array}$ & $\begin{array}{l}3.769 * * * \\
(0.320)\end{array}$ \\
\hline Observations & 29 & 29 & 29 & 29 & 29 & 29 \\
\hline $\mathrm{R}^{2}$ & 0.942 & 0.921 & 0.909 & 0.942 & 0.922 & 0.910 \\
\hline Estimated relative reduction in smoking rate in Canada & $13.5 \%$ & $15.0 \%$ & $16.6 \%$ & $12.1 \%$ & $16.6 \%$ & $19.6 \%$ \\
\hline $\begin{array}{l}\text { Estimated percentage point eeduction in US smoking rate (pre-2001 } \\
\text { benchmark=23.9\%) }\end{array}$ & 3.11 & 3.59 & 3.97 & 2.87 & 3.97 & 4.68 \\
\hline
\end{tabular}


Table 3 Estimated impact of graphic health warning labels: analysing FDA's approach

\begin{tabular}{|c|c|c|c|c|c|c|c|}
\hline Canada* & $\begin{array}{l}\text { FDA's } \\
\text { approach }\end{array}$ & $\begin{array}{l}\text { Model A } \\
\text { replication with } \\
\text { cig taxes }\end{array}$ & $\begin{array}{l}\text { Model B } \\
\text { replication with } \\
\text { official price index }\end{array}$ & $\begin{array}{l}\text { Model C } \\
\text { replication with } \\
\text { actual paid price }\end{array}$ & $\begin{array}{l}\text { Model D } \\
\text { using all obs } \\
\text { with cig taxes }\end{array}$ & $\begin{array}{l}\text { Model E } \\
\text { using all obs with } \\
\text { official price index }\end{array}$ & $\begin{array}{l}\text { Model F } \\
\text { using all obs with } \\
\text { actual paid price }\end{array}$ \\
\hline \multicolumn{8}{|c|}{ Unexplained smoking rates in Canada } \\
\hline Mean pre-2001 period & 0.129 & 0.079 & 0.050 & 0.050 & 0.072 & 0.041 & 0.136 \\
\hline $\begin{array}{l}\text { Mean post-2001 } \\
\text { period }\end{array}$ & -0.501 & -0.253 & -0.116 & -0.812 & -1.777 & -1.194 & -1.574 \\
\hline $\begin{array}{l}\text { Difference } \\
\text { (Post-Pre) }\end{array}$ & -0.630 & -0.332 & -0.165 & -0.861 & -1.849 & -1.234 & -1.711 \\
\hline USAT & FDA & Model A & Model B & Model C & Model D & Model E & Model F \\
\hline \multicolumn{8}{|c|}{ Unexplained smoking rates in the USA } \\
\hline Mean pre-2001 period & -0.010 & 0.001 & 0.000 & 0.000 & 0.085 & 0.112 & 0.125 \\
\hline $\begin{array}{l}\text { Mean post-2001 } \\
\text { period }\end{array}$ & -0.552 & -0.475 & -1.485 & -1.686 & -0.044 & -0.061 & -0.069 \\
\hline $\begin{array}{l}\text { Difference } \\
\text { (Post-Pre) }\end{array}$ & -0.541 & -0.476 & -1.485 & -1.686 & -0.130 & -0.173 & -0.194 \\
\hline $\begin{array}{l}\text { (Canada Difference } \\
\text {-USA difference) }\end{array}$ & FDA & Model A & Model B & Model C & Model D & Model E & Model F \\
\hline \multicolumn{8}{|c|}{ Estimated impact of graphic health warning label on smoking rate } \\
\hline & -0.089 & 0.144 & 1.320 & 0.825 & -1.719 & -1.061 & -1.516 \\
\hline
\end{tabular}

Our estimates are comparable to those found in recent studies that used individual-level population survey data, ${ }^{12}$ as well as simulation models that project the impact of GWLs. ${ }^{23}$ Compared with studies that looked at intermediate outcomes, such as risk perceptions or quit intentions, directly examining the impact of GWLs on smoking prevalence allows us to quantify the impact of GWLs on the number of smokers in a country, something that is critically important to policy makers. More importantly, the quasi-experimental methodology used in this paper allows stronger inferences to be made on the possible causal impact of GWLs on smoking rates.

Our study has several limitations. First, we did not control for differences between Canada and the USA in other tobacco control measures, such as smoke-free air policies, marketing restrictions and anti-smoking media campaigns. The impact of these other tobacco control policies on our estimates will depend on the strength and implementation of these policies in the two countries. If these policies were similar in Canada and the USA during our study period, our estimates of GWLs would not be affected. If policies were becoming stronger in one country relative to the other, our analysis could either overestimate, if policies were becoming stronger in Canada, or underestimate, if the opposite, the impact of GWLs. As a result, the estimated impact of GWLs from our DD models should be interpreted with caution.

Having said that, we believe the strength and implementation of these other policies in the USA were as strong as, if not stronger than, those in Canada during the post-2000 period. For example, while Canada's Tobacco Act's prohibitions on advertising and promotion came into full effect after the introduction of the graphic cigarette labels, at least 41 states, plus the District of Columbia, enacted or substantially strengthened legislation regarding tobacco advertising and promotion, youth access or sampling and distribution between 2001 and 2008. ${ }^{24}$ Similarly, while Canada launched a public education, outreach and mass media campaign that had a goal of reducing tobacco-related death and disease among Canadians in 2001, the American Legacy Foundation launched the 'Truth' Campaign, a nationwide advertising effort aimed at discouraging youth smoking, in 2000 and continued into the 2000s. Canada made significant progress with respect to second-hand smoke protection in the past decade. By 2009, all Canadian provinces and territories had legislated protection from second-hand smoke in enclosed public places and workplaces, up from 5\% of Canadians at the beginning of 2000s. Meanwhile in the USA, 26 states and more than 500 localities in the USA have adopted comprehensive smoke-free policies at bars, restaurants and workplaces since early 1990s. Second, our estimated impact of GWLs on smoking rates is the average impact over the 20012009 period. The impact of GWLs may erode over time as smokers become inured to the labels and the novelty of the GWLs wear off. ${ }^{25}$ Future studies could improve our analyses by accounting for other tobacco control policies and other factors that could influence smoking rates in Canada and the USA, as well as by allowing the impact of GWLs to vary over time.

Despite these limitations, our study demonstrates that adopting large GWLs on cigarette packages reduces smoking prevalence. Our findings have direct relevance to, and implications for, the recent regulatory impact assessment conducted by FDA related to GWLs. The importance of these findings lies in their relevance to the status of GWLs in the USA, where the tobacco industry's challenges to implementation of GWLs have been upheld by the courts. In part, the courts' support of the industry's position derived from a lack of evidence that GWLs would reduce smoking prevalence. That conclusion was based, in part, on the FDA's own inadequate analysis of the impact of the GWLs in Canada.

Our analyses show that FDA's approach to estimating the impact of GWLs on smoking rates is flawed. FDA's estimates are highly sensitive to the changes in variable selection, model specifications, and time period used, and does not permit statistical testing of the impact of GWLs. This study demonstrates the inadequacy of the FDA's analysis, and further shows that a more appropriate analysis indicates that the GWLs have had a statistically significant and practically important effect on actual adult smoking rates. 
Compared to our estimates, and estimates from recent studies using individual level data and simulation methods, FDA's RIA significantly underestimates the likely impact of GWLs in reducing smoking rates in the USA. To the extent that the assumptions and approach employed in FDA's analysis of GWLs becomes the agency's standard, continued use of this approach in FDA's economic analysis may lead to an underestimation of the impact of future proposed rules on tobacco products promulgated by FDA.

Additionally, the fact that we were unable to replicate FDA's estimates indicates a significant problem with transparency and inadequacy of FDA's methods and rule-making process, which need better documentation, including more detailed descriptions of data sources, variable construction and analytical models that are employed. Rectifying these problems before this approach becomes the norm is critical for FDA's effective regulation of tobacco products.

\section{What this paper adds}

- While the literature on the effectiveness of cigarette graphic warning labels (GWL) is substantial, there is limited evidence for their impact on smoking prevalence. This study adds to the growing body of evidence on the effectiveness of GWLs by examining their impact on smoking prevalence.

- This study demonstrates that adopting large GWLs on cigarette packages reduces smoking prevalence. Additionally, our analyses show the Food and Drug Administration's (FDA) approach to estimating the impact of GWLs on smoking rates is inadequate.

Acknowledgements The authors would like to thank Timothy McAfee of the Centers for Disease Control and Prevention for his helpful comments on an early draft of this paper. We thank Cezary T Gwarnicki and Yawen Liu of the University of Illinois at Chicago for their excellent research assistance, and Camille Gourdet and Serj Mooradian of the University of Illinois at Chicago for their legal editorial help.

Contributors FJC, GTF and JH designed the study. GTF and JH collected data. JH conducted data analysis. FJC, GTF and JH contributed to data interpretation. JH, FJC and GTF wrote the first draft; the final version of this paper has been reviewed and approved by all coauthors.

Funding The International Tobacco Control Policy Evaluation Project (ITC) Surveys in the USA and Canada were supported by grants from the U.S. National Cancer Institute (R01 CA100362, P50 CA111236, and P01 CA138389), the Canadian Institutes of Health Research (57897, 79551, and 115016), and the Robert Wood Johnson Foundation (045734). GTF was supported by a Senior Investigator Award from the Ontario Institute for Cancer Research and by a Prevention Scientist Award from the Canadian Cancer Society Research Institute.

Competing interests None.

Patient consent Obtained.

Ethics approval The ITC Surveys in the USA and Canada were cleared for ethics by Research Ethics Boards or International Review Boards at the University of Waterloo (Canada) and Roswell Park Cancer Institute (USA).

Provenance and peer review Not commissioned; externally peer reviewed.

\section{REFERENCES}

1 Hammond D. Health warning messages on tobacco products: a review. Tob Control 2011;20:327-37

2 Fong GT, Hammond D, Hitchman SC. The impact of pictures on the effectiveness of tobacco warnings. Bull World Health Organ 2009:87:640-3.

3 Strahan EJ, White K, Fong GT, et al. Enhancing the effectiveness of tobacco package warning labels: a social psychological perspective. Tob Control 2002;11:183-90.

4 Kees J, Burton S, Andrews JC, et al. Tests of graphic visuals and cigarette package warning combinations: implications for the framework convention on tobacco control. J Public Policy Mark 2006;25:212-23.

5 Hammond D, Fong GT, McDonald PW, et al. Impact of the graphic Canadian warning labels on adult smoking behaviour. Tob Control 2003;12:391-5.

6 Hammond D, Fong GT, McNeill A, et al. Effectiveness of cigarette warning labels in informing smokers about the risks of smoking: findings from the International Tobacco Control ITC Four Country Survey. Tob Control 2006;15(Suppl 3):iii19-25.

7 O'Hegarty M, Pederson LL, Nelson DE, et al. Reactions of young adult smokers to warning labels on cigarette packages. Am J Prev Med 2006;30:467-73.

8 Kees J, Burton S, Andrews JC, et al. Understanding how graphic pictorial warnings work on cigarette packaging. J Public Policy Mark 2010;29:265-76.

9 Hammond D, Fong GT, Borland R, et al. Text and graphic warnings on cigarette packages: findings from the international tobacco control four country study. Am J Prev Med 2007;32:202-9.

10 Thrasher JF, Hammond D, Fong GT, et al. Smokers' reactions to cigarette package warnings with graphic imagery and with only text: a comparison between Mexico and Canada. Salud Publica Mex 2007;49(Suppl 2):S233-240.

11 Borland R, Wilsen N, Fong GT, et al. Impact of graphic and text warnings on cigarette packs: findings from four countries over five years. Tob Control 2009;18:358-64.

12 Azagba S, Sharaf MF. The effect of graphic cigarette warning labels on smoking behavior: evidence from the Canadian experience. Nicotine Tob Res 2013;15:708-17.

13 Miller CL, Hill DJ, Quester PG, et al. Impact on the Australian Quitline of new graphic cigarette pack warnings including the Quitline number. Tob Control 2009;18:235-7.

14 Partos TR, Borland $\mathrm{R}$, Yong $\mathrm{H}-\mathrm{H}$, et al. Cigarette packet warning labels can prevent relapse: findings from the International Tobacco Control 4-Country policy evaluation cohort study. Tob Control 2012;22:e43-e50.

15 Meyer BD. Natural and quasi-experiments in economics. J Bus Econ Stat 1995;13:151-61

16 Angrist JD, Pischke J-S. The credibility revolution in empirical economics: how better research design is taking the con out of econometrics. J Econ Perspect 2010;24:3-30.

17 Roe BE, Just DR. Internal and external validity in economics research: tradeoffs between experiments field experiments natural experiments and field data. Am J Agric Econ 2009;91:1266-71.

18 International Agency for Research on Cancer. IARC Handbooks of Cancer Prevention Tobacco Control Vol. 12. Methods for Evaluating Tobacco Control Policies. 2008;12.

19 Chaloupka FJ, Straif K, Leon ME. Effectiveness of tax and price policies in tobacco control. Tob Control 2011:20:235-8.

20 International Agency for Research on Cancer. IARC Handbooks of Cancer Prevention Tobacco Control Vol. 14. Effectiveness of Tax and Price Policies for Tobacco Control. 2011;14.

21 Centers for Disease Control and Prevention. Current Cigarette Smoking Among Adults - United States 2011. http://www.cdc.gov/mmwr/preview/mmwrhtml/ mm6144a2.htm?s_cid=\%20mm6144a2.htm_w (accessed 24 May 2013).

22 Tobacco Free Kids. Pictorial Warning Labels by Country and Jurisdiction. Pictorial Warning Labels by Country and Jurisdiction. http://global.tobaccofreekids.org/en/ solutions/international_issues/warning_labels/ (accessed 24 May 2013).

23 Levy D, de Almeida LM, Szklo A. The Brazil SimSmoke policy simulation model: the effect of strong tobacco control policies on smoking prevalence and smoking-attributable deaths in a middle income nation. PLoS Med 2012;9:e1001336.

24 Carr T. State Legislated Actions on Tobacco Issues 2009. American Lung Association, 2009

25 Hitchman SC, Driezen P, Logel C, et al. Changes in effectiveness of cigarette health warnings over time in Canada and the United States, 2002-2011. Nicotine Tob Res 2013. In press. 